Revista Iberoamericana, Vol. LXXIV, Núm. 222, Enero-Marzo 2008, 1-

\title{
LA AVENTURA FANTÁSTICA: LA REPRESENTACIÓN COMO CONFLICTO EN JULIO RAMÓN RIBEYRO
}

\author{
POR \\ ENRIQUE CORTEZ \\ Temple University
}

La reflexión sobre lo fantástico es un tema poco frecuente en el quehacer metaliterario de Julio Ramón Ribeyro. ${ }^{1}$ No es el caso de la escritura de los diarios íntimos, de la problemática de la novela, de la historia de la literatura francesa y peruana, de la crítica literaria, o de aspectos de poética presentes en las páginas de La tentación del fracaso (su diario de escritor), de La caza sutil (su colección de ensayos), de Prosas apátridas o Dichos de Luder (libros fragmentarios que ponen al límite las posibilidades del ensayo) o de Cartas a Juan Antonio (correspondencia literaria con su hermano). Esta dispersión genérica, que la crítica pasa inadvertida en su intento de revelar significados trascendentes, ${ }^{2}$ expone un trabajo consciente sobre lo literario al tiempo que atestigua la forja de una estética coherente, aquello que Ribeyro señaló como ausente en su primer crítico sistemático, el alemán Wolfgang A. Luchting (La caza 59).

Esta observación sobre lo fantástico, adquiere una dimensión más significativa si consideramos que Ribeyro inició su narrativa breve, lo más representativo de su obra para la crítica, con cuentos de tipo fantástico. Por ejemplo, uno de sus primeros trabajos publicados, "La huella"3 -aparecido en Letras peruanas en 1952-despliega, como precisa Carlos Eduardo Zavaleta, un tema de Nathaniel Hawthorne. Tomado de los Cuadernos americanos del escritor norteamericano, esta nota proyecta una futura narración que exploraría "el rastro de sangre de un pie desnudo, perseguido por las calles de un pueblo" (69, traducción de Zavaleta). En el texto de Ribeyro, la huella sangrienta dirige al perseguidor a su propia habitación, instalando al personaje en la vacilación -central en la definición de lo fantástico de Tzvetan Todorov- de estar presenciando su propia muerte. Al final, el

\footnotetext{
${ }^{1}$ Existen muy pocas opiniones de Ribeyro sobre sus cuentos fantásticos en el contexto de entrevistas. Como sabemos, en una entrevista el entrevistador impone sus temas al entrevistado, de modo que las interrogantes acerca de lo fantástico son poco frecuentes. Existen opiniones de Ribeyro sobre este tema que revisaremos más adelante, pero adelantamos que se caracterizan por su brevedad y por ofrecer desarrollos poco pensados.

${ }^{2}$ El trabajo de Peter Elmore, quien entiende la escritura de Ribeyro como la construcción de una obra, "un cuerpo de escritura” (29), resulta una excepción interesante, a pesar de su marcado apego a analizar los elementos realistas.

${ }^{3}$ Este y otros cuentos juveniles de Ribeyro son recogidos por Jorge Coaguila en Ribeyro: La palabra inmortal.
} 
personaje entiende que se trata de su muerte, pasando así el sentimiento de duda al lector implícito, quien debe resolver la situación.

La elección de una solución fantástica a una de tipo policial, más coherente con la nota de Hawthorne, invita -me parece-a preguntarse por el papel de la ficción fantástica en la obra de Ribeyro. Se trata de un ejercicio intermitente, presente tanto al inicio de su escritura de narrativa breve como en su etapa de mayor madurez como narrador. Esa intermitencia sobre la que no vuelve, sino de manera marginal-refiriéndose más a la producción de algunos de los cuentos, pero con la ausencia de una reflexión general sobre el tipo de ficción que estos realizaban- ${ }^{4}$ coloca a sus cuentos fantásticos en una orilla de su obra, sugestiva y elocuente, que reúne signos sobre su trabajo y figuración como autor.

El presente artículo examina la manera en que los críticos se han acercado a la presencia de lo fantástico en la obra de Ribeyro, caracterizada en lo medular por utilizar criterios realistas, destacando las lecturas que, desde la aparición de la Antología del cuento fantástico peruano de Harry Belevan, han vinculado sus cuentos con las teorías de lo fantástico. Asimismo, se revisan las ideas de Ribeyro sobre lo fantástico, las cuales revelan un debate metaliterario en el escritor: la indagación acerca de cuál era la representación más adecuada para su literatura y, finalmente, se expone un análisis del cuento “Demetrio”, que a pesar de estar olvidado por la crítica, constituye su texto fantástico más logrado.

REALISMO Y DESVIACIÓN

El comentario y la valoralización de los cuentos fantásticos de Ribeyro desde una perspectiva realista es una constante en la mayoría de trabajos críticos sobre su obra. En el prólogo a la primera edición de La palabra del mudo, titulado "Fantasía y realidad en la obra de Ribeyro”, Washington Delgado destaca el aporte de Ribeyro a la literatura fantástica y lo vincula con Franz Kafka y Jorge Luis Borges, ${ }^{5}$ señalando los elementos diferenciales de sus cuentos, expresados “con notas de ironía triste, de pesimismo melancólico que le dan a esta fantasía cosmopolita y abstracta un aire hondamente personal” (XII). Para Delgado, la visión fantástica y absurda, expresada inmejorablemente, para él, en el cuento "La insignia”, "nos descubre un mundo banal y sin sentido, el mismo mundo, en el fondo, de sus relatos realistas" (XII). Nótese que la perspectiva de lo mismo-el crítico dice "el mismo mundo”-, anula cualquier consideración de la diferencia de la narrativa fantástica, reduciendo el discurso a la historia.

La operación de José Miguel Oviedo es un poco más compleja. Después de recordar que existe una vertiente narrativa paralela a la documental-recuérdese que lo documental está un paso más adelante que el realismo en su representación de lo real y por convención sería más verdadero-, afirma que la expresión fantástica permite jugar a Ribeyro, influido por Kafka, Borges y el mexicano Juan José Arreola, con duplicidades de tiempo y espacio, con objetos enigmáticos y situaciones extrañas (59). No obstante, el crítico declara que ni

${ }^{4}$ No es el caso de sus cuentos llamados realistas, objeto de análisis ya desde el prólogo de su primer libro Los gallinazos sin plumas de 1955.

${ }^{5}$ Esta filiación de influencia es ya un lugar común que posteriormente se ha repetido en diversos estudios críticos, pero sobre todo en las entrevistas hechas al autor. Véase la selección de entrevistas realizadas a Ribeyro, editada por Jorge Coaguila. 
la descripción de lo social ni la dimensión sobrenatural es lo sustantivo en su obra. Más bien es el tono de su visión del mundo, definido como una impalpable melancolía (59).

En "Los cuentos de Ribeyro", 6 Julio Ortega argumenta que una serie de los cuentos del autor "podrían ser leídos como distintos ensayos dentro de la 'narrativa fantástica,' donde introducen con una escritura neutral la extrañeza y la ironía (como en 'La insignia'), a la vez que un comentario sumario sobre el sinsentido social” (128, mi énfasis). La calidad de ensayos, como califica a estos cuentos Ortega, alude más al carácter inacabado de estos y al hecho de que no sean los más representativos, porque para el crítico, también partiendo desde el realismo, lo fantástico en Ribeyro es un tipo de percepción social, que muestra la aventura poco heroica de sus personajes (129). En otras palabras, aún en el relato fantástico Ribeyro es realista: la ficción fantástica le permite mostrar el fracaso social. ${ }^{7}$

Pero el más importante acercamiento a los cuentos fantásticos de Ribeyro desde una perspectiva realista se lo debemos a Luis Fernando Vidal, quien clasifica su narrativa en dos niveles. De una parte, destaca una vertiente configurativa, que incluye una modalidad inventiva -textos de denuncia, que expresan un compromiso de tipo sartreano- y una modalidad evocativa-conformada por cuentos que expresan un claro cariz nostálgico: una niñez pequeño burguesa y autocomplaciente-. Ambas modalidades, afirma Vidal, se articulan semánticamente por oposición, la dicotomía oficialidad/marginalidad, configurando un espacio textual muy cercano al referente (78-79).

La vertiente desviatoria, que no es un ejercicio interrumpido ni menos importante, según aclara Vidal, ${ }^{8}$ se caracteriza porque instala al lector "en el reino de la lejanía contemplativa y, por lo mismo, estática, frente a un narrador que sorprende con sus abstracciones, exotismo y hasta con los finales inesperados de las historias” (79). Vidal considera que esta vertiente se opone a la concreción configurativa o realista que logra construir un referente peruano, pues en los cuentos desviatorios "la ficción desdobla el tiempo, enajena la especialidad, altera la lógica de los sucesos, surca lo inexplicable y lo

\footnotetext{
${ }^{6}$ Una parte de este artículo apareció como prólogo a la edición de Cuentos completos de editorial Alfaguara en 1994. El único detalle es que lleva la firma del escritor, y gran amigo de Ribeyro, Alfredo Bryce Echenique. Al respecto, en un correo personal, Julio Ortega me aclara el tema: "Sí, qué divertido que te hayas dado cuenta de lo de Bryce y el prólogo a Ribeyro. Alfredo me pidio permiso para firmar ese fragmento y yo se lo di, encantado, ya que era una buena broma literaria, producto de nuestra complicidad. Lo que sí es absurdo es que dos supuestos expertos en Bryce lo hayan incluido, como de Bryce, en un tomo de ensayos dedicados a Julio en la Católica”. El crítico se refiere a Asedios a Julio Ramón Ribeyro, colección de ensayos sobre la obra del escritor, editada por César Ferreira e Ismael P. Márquez.

${ }^{7}$ Existen otras lecturas que atienden algunos aspectos de la narrativa fantastica de Ribeyro, pero sin realizar una crítica diferenciadora en estos textos de las líneas generales de interpretación que se ha hecho de la obra realista de Ribeyro, a saber: crítica social y escepticismo. En esta dirección pueden leerse los artículos de María Rosario Alfani, "Escritura en contumacia: La escritura horizontal de Julio Ramón Ribeyro", y el de Efraín Kristal, "El narrador en la obra de Julio Ramón Ribeyro”; también los apuntes críticos dedicados a los cuentos fantásticos en los, relativamente recientes, libros de James Higgins, Cambio social y constantes humanas, y de Peter Elmore, El Perfil de la palabra.

${ }^{8}$ Aclaración, por lo menos paradójica, dado que la llamada vertiente desviatoria tiene sólo un par de párrafos de desarrollo, frente a las 12 páginas que analizan la vertiente configurativa.
} 
absurdo, asoma a los linderos del vacío” (79). En consecuencia, la identificación de dos líneas creativas marcadamente distintas en la obra de Ribeyro, permiten a Vidal indicar "la huella de una honda contradicción” (80, mi énfasis), definida por la “coexistencia de concepciones contrapuestas de lo literario, cuya plasmación presenta estilemas que a través de tales contradicciones configuran obra y autor" (80). Conviene aclarar que la lectura de Vidal que propone la separación de dos líneas creativas en Ribeyro y, por cierto, desde donde el crítico puede postular una honda contradicción en la construcción de la obra es sobre todo metodológica y, en ese sentido, es un reproche más de tipo preceptivo que crítico.

No obstante, la contradicción constituye la obra de Ribeyro y, en la perspectiva de este trabajo, la enriquece. De hecho, podemos entender esta ilogicidad como el significante de una búsqueda por la escritura donde la coherencia de un tema, el logro de un estilo, la fidelidad a un género se tornan aspectos de una obra, en este caso, contrapuestos o en diferente dirección, pero jamás su motor, pues como nos recuerda el propio Ribeyro:

Las fronteras entre los llamados géneros literarios son frágiles y catalogar sus textos en uno u otro género es a menudo un acto circunstancial, pues toda obra literaria es en realidad un continuum. Lo importante no es ser cuentista, novelista, ensayista o dramaturgo, sino simplemente escritor. (Antología personal 8, énfasis del autor) ${ }^{9}$

LA ORILLA FANTÁSTICA

El gesto crítico más importante para establecer una tradición fantástica en el Perú lo constituye la Antología del cuento fantástico peruano de Harry Belevan. Esta selección postula la existencia de una tradición fantástica en las letras peruanas desde las primeras décadas del siglo xx, con autores como Clemente Palma, Ventura García Calderón, Abraham Valdelomar y, entre ellos, Ribeyro es destacado "como el más importante cuentista contemporáneo” (130). La introducción que Belevan presenta en este libro sitúa, paratextualmente, en otro espacio de lectura -la ficción fantástica- textos que antes no habían sido considerados como tales. Así cuentos como "Doblaje”, "Ridder y el pisapapeles" y “Los jacarandás”, son presentados desde la teoría de lo fantástico. Pero a esta presentación le falta el análisis puntual que sólo aparecerá, casi dos décadas después, en la tesis de doctorado de Jesús Rodero sobre la obra de Ribeyro. El libro, producto de esta tesis, contiene un capítulo dedicado a sus cuentos fantásticos e invita a pensar en el tipo de narrativa fantástica que los textos del peruano proponen. ${ }^{10}$

En efecto, Rodero ha evaluado las líneas teóricas sobre lo fantástico para concluir que este se define no sólo por esa transgresión de las normas, idea explorada por Irene Bessière y Rosie Jackson, "sino también por la presencia de algún elemento irreal, improbable e inverosímil que problematiza la realidad narrada y pone en cuestión tanto lo real como lo irreal. Es esta vacilación en la interpretación y esa recusación mutua de lo real y lo irreal lo que nos acercaría al modo fantástico” (76). Para Rodero, la definición anterior corresponde

${ }^{9}$ También citado por Peter Elmore al inicio y al final de su primer capítulo de El Perfil de la palabra.

${ }^{10}$ Este capítulo generó un artículo que apareció en la Revista Iberoamericana en 2000. Usamos esta última versión, dado que está revisada y tiene algunas mejoras en la redacción. 
a lo neofantástico y es el espacio donde ubica a la narrativa de Ribeyro. Se trata de una fórmula aplicable a algunos cuentos de Ribeyro, pero como demostraremos más adelante no es adecuada para todos los cuentos, pues como nos recuerda Roland Barthes en $S / Z$ todo texto construye su modelo. ${ }^{11}$

En otras palabras, la clasificación de neofantástico, que Rodero propone para los cuentos fantásticos de Ribeyro, tiene el alcance de su posicionamiento teórico y en última instancia me parece falible porque el crítico concibe lo neofantástico como lo fantástico complejo, entendiendo lo fantástico simple como la definición de Todorov. Quiero decir, que la noción de neofantástico, término apuntalado por Jaime Alazraki -y a quien Rodero no tiene en cuenta a juzgar por su bibliografía- resulta de la determinación histórica que Todorov da al género fantástico, es decir, como una forma de escritura propia del siglo xix: "la literatura fantástica no es más que la mala conciencia de ese siglo xix positivista” (citado por Roas 33). Recordemos que para Todorov “lo fantástico es la vacilación experimentada por un ser que no conoce más que las leyes naturales, frente a un acontecimiento en apariencia sobrenatural” (48). Esta vacilación o duda con el acontecimiento perturbador representa lo fantástico puro cuando el personaje y el lector implícito no consiguen elaborar una explicación; nos ubica en lo extraño o insólito cuando esa explicación se propone racional y nos instala en lo maravilloso cuando nos presenta una explicación sobrenatural (66-68). Existen matices para el teórico búlgaro, como lugares intermedios entre lo extraño y lo fantástico o entre lo fantástico y lo maravilloso, que hacen de su definición una herramienta muy operativa, pero insuficiente según señalan los trabajos de Bessière o Jackson, como el mismo Rodero apunta (74). Ahora bien, Todorov constata que en algunas narraciones del siglo xx, La Metamorfosis de Kafka sobre todo, "el acontecimiento sobrenatural ya no produce ninguna vacilación porque el acontecimiento descrito es, según Todorov, totalmente extraño, tan anormal como el acontecimiento que le sirve de fondo” (Roas 34). Sin embargo, al basar Todorov su teoría de los géneros en un criterio determinista de la historia, el teórico olvida reconocer que la historia es también una construcción llena de violencias y silencios, resultando muy problemático establecer relaciones de verdad entre la realidad y los discursos. Al contrario, el teórico apunta que “cada época tiene su propio sistema de géneros, el cual está en relación con la ideología dominante, etc. Como cualquier otra institución, los géneros evidencian los rasgos constitutivos de la sociedad a la cual pertenecen” (Los géneros 54). ${ }^{12}$

\footnotetext{
${ }^{11}$ Dice Barthes: "El comentario de un solo texto no es una actividad contingente, colocada bajo la coartada tranquilizadora de lo concreto: el texto único vale por todos los textos de la literatura, no porque los represente (los abstraiga y los equipare), sino porque la literatura misma no es nunca sino un solo texto: el texto único no es acceso (inductivo) a un Modelo, sino entrada a una red con mil entradas; seguir esta entrada es vislumbrar a lo lejos no una estructura legal de normas y desvíos, una Ley narrativa o poética, sino una perspectiva (de fragmentos, de voces venidas de otros textos, de otros códigos), cuyo punto de fuga es, sin embargo, incesantemente diferido, misteriosamente abierto: cada texto (único) es la teoría misma (y no el simple ejemplo de) de esta fuga, de esta diferencia que vuelve indefinidamente sin conformarse" (8, énfasis del autor).

${ }^{12}$ Dado que este artículo no es el lugar para iniciar una discusión genológica, sólo quiero apuntar que la noción de lo neofantástico asume sin discusión ese determinismo histórico, que al final juega en su contra, pues limita su capacidad descriptiva a los términos ya visualizados por el
} 
En consecuencia, me parece claro que si Rodero hubiera partido de Bessière, no podría haber calificado a Ribeyro como neofantástico, pues esta autora señala que el relato fantástico se caracteriza por usar datos contradictorios, reunidos por la coherencia del ejercicio narrativo, lo cual nos hace arribar a una forma paradójica (que podríamos entender como lo fantástico complejo). El relato fantástico, precisa Bessière, "utiliza los marcos sociológicos y las formas del entendimiento que definen los dominios de lo natural y lo sobrenatural, de lo trivial y lo extraño, no para inferir una certeza metafísica sino para organizar la confrontación de los elementos de una civilización relativos a los fenómenos que escapan a la economía de lo real y surreal, cuya concepción varía según las épocas” (85, énfasis de la autora). En otras palabras, el relato fantástico resulta a todas luces complejo, paradójico, y esto es consecuencia no de la inverosimilitud de esta narración, sino de la yuxtaposición y las contradicciones de los diversos verosímiles de una época que este relato reúne en una especie de examen intelectual: esta operación de síntesis instala la sinrazón, precisa Bessière, “en la medida misma en que concierta el orden y el desorden, que el hombre adivina en lo natural y sobrenatural, bajo el signo de una racionalidad formal” (86).

Más reciente es el trabajo de Giovanna Minardi, quien en su libro La cuentística de Julio Ramón Ribeyro dedica un capítulo a la temática fantástica. La autora, al igual que Rodero, hace un estado de la cuestión de la teoría de lo fantástico y califica a la totalidad de los cuentos de tipo fantástico de Ribeyro como extraños, fiel a la metodología de análisis propuesta por Todorov. A esta conclusión le ayuda una opinión del mismo Ribeyro, enunciada en una entrevista, según la cual sus cuentos no pertenecen a lo fantástico típico, sino exploran la dimensión de lo insólito (Minardi 74-75). Estos cuentos extraños, presentan un conjunto de características que Minardi enumera para nosotros y de las cuales, la más importante en mi opinión está vinculada a lo extraño. Dice Minardi: "lo extraño tiene una triple función: 1) ontológica, en el sentido de la imposibilidad del alcance del conocimiento único y absoluto; 2) sociopolítica, en el sentido de crítica sutil, subterránea al sistema de poder; 3) psicológica, en el sentido de predominio de la realidad psíquica, mental de los personajes” (76). Sólo queda agregar que todos estos puntos, lugares comunes de la crítica realista a la obra de Ribeyro, es decir, como identificación de un filón escéptico, del eje marginalidad/oficialidad y psicologismo, hubieran tenido un nivel de mayor profundización partiendo del trabajo de Rosie Jackson, quien a diferencia de Todorov (al cual permanece demasiado cerca Minardi) atiende mejor el nivel ideológico del relato fantástico. No obstante, esta definición de lo extraño según su funcionalidad, que inscribe sus hallazgos en las conclusiones de la crítica anterior de la obra de Ribeyro, no se desprende tampoco de la lectura de Washington Delgado, quien en el prólogo citado líneas arriba, indica que "La insignia”, "nos descubre un mundo banal y sin sentido, el mismo mundo, en el fondo, de sus relatos realistas” (XII). Minardi refiere, olvidando citar a Delgado, que "los cuentos fantásticos ribeyrianos, en el fondo, no se diferencian mucho de los cuentos realistas por una simple razón: la banalidad” (74, énfasis de la autora).

propio Todorov en su análisis de Kafka. De hecho, la definición de Alazraki, recoge la referencia al psicoanálisis de Todorov como uno de los elementos que transforman el género fantástico: "el relato neofantástico está apuntalado por los efectos de la primera guerra mundial, por los movimientos de la vanguardia, por Freud y el psicoanálisis, por el surrealismo y el existencialismo, entre otros factores” (Alazraki 280). Así, inscribe su noción de neofantástico en la cronología propuesta por Todorov. 


\section{LA TENTACIÓN DE LO FANTÁSTICO}

No son frecuentes los comentarios de Ribeyro sobre lo fantástico. En 1973, en un conversatorio realizado en el Instituto Nacional de Cultura del Perú y transcrito por el crítico Wolfgang Luchting con el título "Lo que dijo Ribeyro”, el autor de La palabra del mudo dice: "siempre he escrito mis cuentos como unidades independientes. No encuentro ningún desarrollo orgánico. Más bien están agrupados en 'familias de preocupaciones’. Así, 'La huella’ es del género fantástico” (39). En este mismo diálogo, Ribeyro señala que "una segunda vertiente sería el cuento realista", una tercera "los cuentos evocativos, autobiográficos” y una cuarta “los cuentos “europeos”” (39). Nótese que esta clasificación pone en primer lugar al género fantástico y diferencia tres líneas narrativas más, entrecruzadas a lo largo de su obra: vertientes, como las llamará también dos años después Vidal, ${ }^{13}$ que muestran la dispersión de intereses creativos del autor de La palabra del mudo.

Pero la honda contradicción, destacada por Vidal, entre el realismo y otras formas de representación en que parece oscilar la búsqueda creativa de Ribeyro se expresa de manera clara en la entrevista que concedió en 1994 al periodista Mito Tumi:

No estoy muy seguro de haber escrito cuentos fantásticos. Entiendo por cuento fantástico un cuento que es puro producto de la imaginación, en el cual las referencias a la realidad son escasas. En cambio, mis cuentos que son considerados fantásticos están apoyados siempre en hechos reales que he conocido o vivido, pero en los cuales hay siempre un momento en que la historia se dispara un poco hacia lo insólito o inesperado. No es el cuento fantástico típico, se trata de un cuento realista que patina o se desliza de pronto en otra dimensión, la dimensión de lo insólito. (293)

Si se sigue esta cita, no resulta difícil caer en la tentación de ubicar a Ribeyro según el esquema de lo fantástico de Todorov. De hecho Minardi lo hace, como se ha visto líneas atrás. Pero lo que Ribeyro llama la dimensión de lo insólito, no corresponde necesariamente a lo insólito según Todorov, sino a lo que el crítico búlgaro llama lo fantástico puro, pues la explicación racional, condición de lo insólito, jamás se produce en los cuentos de Ribeyro. Además, la idea de relato fantástico de Ribeyro, “un cuento que es puro producto de la imaginación, en el cual las referencias a la realidad son escasas” (293) hace pensar en lo que Todorov denomina maravilloso. En el fondo, para Ribeyro la realidad es estática y se puede conocer; los hechos reales de los que habla tienen ese estatus de realidad porque han sido vividos. Su modelo de realidad, en consecuencia, tiene mucho en común con la idea de realidad explorada por los escritores realistas del siglo xix, de los que fue un gran lector. Por supuesto que existen contrastes vinculados a la formación, las diferencias de época, de historia, de geografía, en suma, a la experiencia del tiempo y el espacio; sin embargo, en el tratamiento

\footnotetext{
${ }^{13}$ Este apunte nos lleva a otro tema, el escritor como crítico de su obra, pues el propio Ribeyro da con el calificativo de "vertientes" mucho antes que Vidal. Además, en el caso de Ribeyro es claro que muchos criterios críticos -la noción de escepticismo para definir la personalidad literaria de su obra es la más importante- son cosecha del propio autor, las cuales los críticos han repetido, aproblemáticamente, como claves de interpretación. Un caso similar, y de hecho más claro, es el de Mario Vargas Llosa. Este caso ha sido estudiado por el noruego Birger Angvik en su libro La narración como exorcismo: Mario Vargas Llosa, obras (1963-2003).
} 
que hace de sus personajes, el sentimiento del fracaso tan presente en su narrativa, pero también en su diario íntimo, surge de una inadecuación entre el universo ideológico de estas personas literarias y la inestabilidad del mundo, de lo real. En otras palabras, la visión del mundo ribeyrano es moderna; la realidad en que circulan sus personajes (como también el sujeto del discurso de su diario) se revela posmoderna, entendiendo este último término como la vida en "un universo totalmente incierto, en el que no hay verdades generales, puntos fijos desde los cuales enfrentarse a lo real: el 'universo descentrado' al que se refiere Derrida. No existe, por lo tanto, una realidad inmutable porque no hay manera de comprender, de captar qué es la realidad” (Roas 36). ${ }^{14}$ Puede, por lo tanto, precisarse que en los cuentos de Ribeyro no es la realidad la que resulta trasgredida, sino el universo ideológico de los personajes. Esto genera una imposibilidad de respuesta ante el acontecimiento y sitúa a los personajes en una suerte de vacilación constante. Llamar a esta sensación escepticismo es una verdad a medias que pierde de foco el lugar incierto en que ubica a los personajes de Ribeyro el desfase entre ideología y realidad.

En su correspondencia con su hermano, esta indagación sobre el tipo de representación que debía lograr su escritura tiene momentos interesantes, pero están más enfocados a evaluar las posibilidades del cuento y la novela y hay momentos en que este último género tiene una valorización muy positiva. En una carta del 12 de marzo de 1955, Ribeyro le dice a su hermano, Juan Antonio: "Por razones muy personales me resulta sumamente difícil escribir una novela. Para mí la novela es la forma máxima de la expresión literaria y por este motivo no debe reducirse a un mero cuadro objetivo, sino que debe revelar una visión de mundo” (73). Otra vez, una noción de la novela muy decimonónica que problematiza el sentido de la poética realista. Según se desprende de lo dicho, no se trata de caer en el documentalismo, implícito en su expresión “cuadro objetivo” (Ribeyro debió estar pensando en el naturalismo), sino presentar "un código moral, del cual pueda desprenderse un modo de vida" (73).

Esta indagación acerca del realismo, la novela y el cuento, reflexión metaliteraria de fondo en la correspondencia, también tiñe muchas páginas de La tentación del fracaso, el diario de escritor de Ribeyro. Se trata de una temática que relega hacia la indiferencia, en la medida que la crítica lo catapulta como escritor realista, indagaciones sobre la representación fantástica. En efecto, esa indecisión acerca de la representación se expresa claramente en un apunte de su diario de mayo de 1967, donde considera que sus cuentos autobiográficos están inscritos en "un tono fundamental, que es lo que dará a todo lo mío su coloración definitiva” (330). Después de mencionar algunos de estos cuentos, como "Páginas de un diario", dice:

Quizás esa sea mi verdadera voz. ¡Pero también hay otras! Es como si existiera en mí no uno sino varios escritores que pugnaran por expresarse, que quieren hacerlo todos al mismo tiempo, pero que no logran a la postre más que asomar un brazo, una pierna, la nariz o la oreja, alternativamente, en desorden, abirragados y un poco

\footnotetext{
${ }^{14}$ La distinción entre moderno y posmoderno suele ser bastante problemática y, en términos generales, estoy de acuerdo con las conclusiones que ofrece Roas de la bibliografía al respecto. Su lectura, en consecuencia, me resulta operativa, dado que lo contrario, una lectura personal de lo posmoderno, no aportaría mucho a este estudio.
} 
grotescos. Por eso, actualmente, me mantengo un poco a la expectativa, sin querer tomar parte en esta lucha, con la esperanza de que alguno de estos homúnculos se sobrepongan, sacrificando a los demás, salvo que en la pelea todos perezcan y no me quede otro partido que el silencio. (330, mi énfasis)

La honda contradicción identificada por Vidal es definida por Ribeyro como una lucha, una pelea que ocurre dentro de sí a pesar suyo y que lo acerca al silencio, esto es, a lo irrepresentable. En su intento por afinar su realismo apuesta por la novela, a la que concibe como la forma máxima de la expresión literaria, como se ha visto líneas arriba, y se muestra no sólo incrédulo de la eficacia de una expresión no realista, sino también del cuento, género en que alcanzó maestría ejemplar en el Perú e Hispanoamérica. En un apunte del 27 de diciembre de 1977, en la espera de la edición del tercer tomo de La palabra del mudo, a pesar de afirmar que se trata de su mejor colección de cuentos, se muestra muy inseguro de su logro: "estoy ya convencido de que empleo un género muerto, sin curso en nuestra época. Serán pues curiosidad, puro anacronismo, entrega a los cada vez más raros lectores de relato corto" (592). Este convencimiento, consciente de la época, se explica en el éxito que tuvo la novela en las décadas de 1960 y 1970 en el contexto hispanoamericano. Los autores del llamado boom, muchos de los cuales fueron amigos de Ribeyro, según se consigna en muchas páginas de La tentación del fracaso, marcaron un horizonte de expresión del cual Ribeyro nunca se pudo desmarcar. Así su narrativa se instala en una tensión por la representación que se resuelve, por lo menos para él, en un cuento que está a medio camino entre representación realista y fantástica. Me refiero a "Silvio en el Rosedal”, narración mediana, diríase una nouvelle, que el propio Ribeyro considera su mayor logro-“"'Silvio’, el mejor que he escrito” (La tentación 603). Se trata de un texto, inexplicable sin ese debate sobre la representación y que se complementaría mejor si es analizado desde la orilla fantástica. ${ }^{15}$

“DEMETRIO”, ANÁLISIS DE UN CASO

La suerte crítica de "Demetrio" es extraña. A pesar de reunir elementos expresivos que permiten una tensión única, me refiero a la retórica del diario íntimo que dota a la narración de una punzante verosimilitud (con una tensión parecida a la de "Chac Mool” de Carlos Fuentes, que utiliza la misma forma genérica), ha sido sistemáticamente ignorado por varios críticos que se han ocupado de lo fantástico de Ribeyro. Tanto James Higgins (153-155) como Gerardo García Muñoz (89-93) presentan análisis puntuales de este cuento, que se caracterizan por la ausencia de referencias a la teoría de lo fantástico; mientras sólo existen referencias de pasada de este cuento en los trabajos de Elmore (206) y Minardi (87). En cambio, Rodero, quien con mayor seriedad ha explorado esta línea narrativa de Ribeyro, no lo menciona en absoluto.

El propio Ribeyro escribe en su diario, a propósito de la organización del tercer volumen de La palabra del mudo, 6 de diciembre de 1975, que esta colección tendrá que integrarla con antiguos cuentos que reescribe muy parcialmente, “cambiando aquí y allá alguna

${ }^{15}$ Los críticos también han celebrado esta narración y hay muchas páginas de análisis que destacan los cruces entre autobiografía, poética y escritura. Me parece que Ortega, Higgins y Elmore ofrecen las páginas más sugestivas. 
palabra, como ‘Demetrio' o ‘El carrusel', el primero de los cuales lo escribí hace 22 años; nada menos. Esto se debe a que el cuento [ 'Demetrio'] ya no me dice nada, como forma de expresión; es un género caduco” (473). Esta caducidad a la que se refiere Ribeyro, debe ser entendida como expresión de ese debate sobre la representación en que se instala su obra, y que tiene en “Demetrio” la expresión relegada del polo fantástico. No obstante, se trata de una postergación que anuda la obra y tiene la forma de un acto fallido, en el lenguaje del psicoanálisis, que formula mejor su proceso de escritor. Veamos el inicio de "Demetrio":

Dentro de un cuarto de hora serán las doce de la noche. Esto no tendría ninguna importancia si es que hoy no fuera el 10 de noviembre de 1953. En su diario íntimo Demetrio von Hagen anota: "El 10 de noviembre de 1953 visité a mi amigo Marius Carlen”. Debo advertir que Marius Carlen soy yo y que Demetrio von Hagen murió hace exactamente ocho años y nueve meses. (481)

A diferencia del cuento fantástico tradicional, donde el elemento fantástico irrumpe en el universo realista, generando una alteración de las reglas que rigen este tipo de representación, “Demetrio” nos confronta de entrada ante un problema: el narrador y personaje (narrador autodiegético en la terminología de Genette), Marius Carlen, nos informa preocupado que su amigo Demetrio von Hagen, quien murió hace ocho años y nueve meses, anuncia en su diario íntimo haberlo visitado ese día. En otras palabras, el narrador instala al lector desde el inicio en una situación paradójica, en un universo complejo, espacio que se le presenta como un enigma: "se trataba más bien del principio de un interesante enigma”(481).

Esta situación paradójica, característica fundamental del relato fantástico para Bessière, se complica aún más, cuando el anuncio de la visita de Demetrio tiene como contexto comunicativo un diario íntimo. En el artículo “En torno a los diarios íntimos”, que según las fechas fue escrito por Ribeyro en la misma época en que redactó “Demetrio” (1953), ${ }^{16}$ Ribeyro afirma que la escritura de diarios constituye un género literario. Se trata de un texto fundador para la teoría de este género en el mundo hispano e identifica aspectos cruciales de la llamada literatura íntima que años más tarde explorarán con atención teóricos como Phillippe Lejeune. ${ }^{17}$

${ }^{16}$ Este artículo fue muy importante para las gestiones del joven Ribeyro. En una carta del 12 marzo de 1955 le pide a su hermano, Juan Antonio, que le remita una copia del artículo aparecido en El Comercio a Madrid (Cartas 72) y desde Alemania, un año después, le cuenta a su hermano que tiene esperanzas de recibir una beca en Paris pues ya sabe francés y, además, M. Berveiller, posiblemente quien definía la concesión de la beca, había leído por "casualidad mi artículo sobre diarios íntimos” (Cartas 101). Se trató de una lectura más que casual, afortunada, porque pocos meses después tal beca le fue concedida.

${ }^{17}$ En efecto, la primera característica que Ribeyro identifica en todo diario es la cotidianidad. La segunda afirma que todo diario se funda -escribe y lee- "en el principio de veracidad o por lo menos de una presunción de veracidad. Es necesario admitir a priori que los hechos consignados en el diario son verdaderos. Queda luego al arbitrio del lector o del erudito demostrar lo contrario" (10, énfasis del autor). Por cierto, Leujene llamará a este presunto principio de veracidad "pacto autobiográfico", siempre y cuando el texto nos presenta una identidad entre autor, narrador y personaje, cuestión que todo diario cumple (Lejeune 48). Un tercer punto lo constituye para Ribeyro la "libertad de composición o, en otras palabras, la casi inexistencia 
Alpresentarse como una narración compleja, pues reúne de manera clara la verosimilitud del cuento con la del diario íntimo (sin duda esta última es mucho más efectiva), “Demetrio" nos revela al narrador y al narratario en una situación paradójica. Este estado paradójico se deriva no de la inverosimilitud del relato fantástico, "sino de la yuxtaposición y las contradicciones de los diversos verosímiles, es decir, las vacilaciones y las rupturas de las convenciones colectivas sometidas a examen” (Bessière 86). Hay que advertir que la verosimilitud de "Demetrio", reforzada por el pacto autobiográfico en que el narrador se encuentra instalado, es una operación, que Jean Bellemin-Noël llama fantasmagórica y que en su lectura es la raíz de todo lo imaginario: "se trata, en definitiva, de fabricar lo designado con lo significado, o, si se prefiere, de hacer creer en un referente mediante una cierta forma de manipular los signos. El objetivo buscado es que el lector sitúe 'alguna cosa' tras las palabras" (138, énfasis del autor).

En “Demetrio”, como en todo texto fantástico, lo paradójico es un resultado más que un efecto. La reunión de diversos verosímiles responde al intento del escritor de generar un efecto de verdad incontrastable. Esta reunión surge de la escritura, de la lógica particular de la narrativa que puede juntar lo racional y lo irracional en una sola forma. En el cuento de Ribeyro, la verosimilitud del fantasma que es una de las posibilidades de existencia de Demetrio; la verificación de su muerte, gracias a una exhumación y que nos remite a una verosimilitud científica; la existencia de varios tiempos de realidad, que parece desprenderse de la teoría de la relatividad, complejizan de modo irresoluble la historia. Al poner en escena la diversidad y la exclusión recíproca de las creencias que tienen lugar en 1950, lo fantástico acontece en "Demetrio" como algo muy singular. Su estrategia es realizar un desmontaje de lo real -o si se prefiere, una deconstrución-, no desde una argumentación intelectual, sino evidenciando un conjunto de sistemas de significación que coexisten en un momento dado y que reunidos, en el relato, no pueden expresar lo real: Después de una investigación en que el narrador verifica como ocurridos todos los hechos consignados en el diario de Demetrio von Hagen, escrito por adelantado según los periodistas que lo examinaron primero, él se muestra muy vacilante. Escribe: “Es evidente que Demetrio murió el 2 de enero de 1945, pero también es cierto que en 1948 asistió al entierro de Ernesto Panclós, que en 1949 estuvo en el Museo Nacional de Oslo y que en 1951 conoció en Freimann a Marion y tuvo con ella un hijo. Todo ello está debidamente verificado" (483). "Demetrio”, siguiendo a Beissière, nos muestra que no existe un lenguaje propiamente fantástico, sino que éste, en la medida que opera como una deconstrucción, se puede leer como el reverso del discurso sobre el cual opera, sea este teológico, iluminista, espiritualista, psicopatológico (87). En consecuencia, no podemos decir que el contenido de un texto fantástico realiza significaciones religiosas o cognitivas, dependiendo de la materia sobre la que opera. Al contrario, una vez inscritas en el relato fantástico las significaciones religiosas o iluministas, por señalar dos, se vuelven elementos del mundo propuesto por el texto y nada tienen que ver con la significación de sus dominios de origen, pues al ser trasladados a la narración obtienen otro sentido, que para Beissière es el signo más claro de la autonomía de lo fantástico: "El relato

de una técnica específica del diario íntimo” (11, énfasis del autor). Un último aspecto nos remite al carácter inconcluso de todo diario, lo cual nos habla más de la marca de un destino que de la elección personal. "De allí -precisa el autor- el sentimiento de inseguridad, de incertidumbre y de desamparo que palpita en todo auténtico diario íntimo” (12). 
fantástico recoge y cultiva las imágenes y los lenguajes que, en un área sociocultural, parecen normales y necesarios para fabricar lo absolutamente original, lo arbitrario” (88). En "Demetrio", lo que se deconstruye es la idea del tiempo.

En efecto, el elemento que sitúa en la paradoja al narrador, y por consiguiente al narratario, que comparte las mismas convenciones del primero, es el tiempo, y su indagación se da en varios planos. En primer lugar, Marius Carlen analiza las consecuencias racionales que la existencia de Demetrio supone para el mundo real. Su dilucidación atañe a la manera en que comúnmente concebimos el tiempo:

El calendario oficial me ha llegado a parecer, después de lo ocurrido, una medida convencional del tiempo, útil solamente como referencia a hechos contingentes vencimientos de letras de cambio, efemérides nacionales- pero completamente ineficaz para medir el tiempo interior de cada persona, que es en definitiva el único tiempo que interesa. Nuestra duración interior no se puede comunicar, ni medir ni transferir. Es factible vivir días en minutos e inversamente minutos en semanas. (483)

El tiempo personal, el único que interesa al narrador, se le presenta como un problema pues no se explica cómo puede trasladarse la duración subjetiva a la realidad, “cómo se concilia el tiempo de cada cual con el tiempo solar. Es muy corriente pensar muchas cosas en un segundo, pero ya es más complicado hacerlas en ese lapso. Y lo cierto es que Demetrio von Hagen hizo muchísimas cosas en su tiempo personal, cosas que se cumplieron sólo después en su tiempo real” (483). Marius Carlen añade que el diario señala algunas cosas más por hacerse, como visitarlo ese día.

Otra línea de indagación de la problemática del tiempo es la enunciación. Bellemin-Noël inicia sus notas sobre lo fantástico explorando un tema central en este tipo de narrativa -y también en el desarrollo de “Demetrio”-, la cuestión del narrador. Para el teórico francés, el narrador funciona como un enlace, pero también como una censura, ${ }^{18}$ entre el acontecimiento fantástico y su ocurrencia en la normalidad vivencial de un protagonista. Así se instituye como testigo, que puede ser de sí mismo si el protagonista es él. En todo caso, el relato fantástico funciona en la posterioridad, enfatiza Bellemin-Noël, pues quien narra no está presente en el momento en que ocurre el acontecimiento fantástico (124). El teórico precisa que "el narrador puede aparecer también como idéntico al protagonista: la misma instancia, la misma voz, pero más tarde, una vez llegado el sosiego" (125). En "Demetrio", acontecimiento y enunciación terminan por coincidir, lo cual es una prueba en contra para el teórico. El narrador autodiegético, inicia su historia situándonos ante el hecho fantástico: un diario predictivo. Y si bien es cierto, como dice Bellemin-Noël, que el narrador habla de sí como separado de sí, el acercamiento entre sujeto del discurso y sujeto de la enunciación es un proceso -temporal- que la escritura pretende captar como un lugar de encuentro al final del cuento.

${ }^{18}$ Bellemin-Noël usa este término entre comillas, pues la idea de censura, que es sobre todo una manifestación política de lo ideológico, también se da en el campo de la psique: "el sueño, por ejemplo, se constituye, de entrada, como censurado” (130). 
La escritura como lugar de encuentro de otros tiempos y otras escrituras es algo que está muy claro en "Demetrio”. El también escritor Marius Carlen -que no dice serlo, pero escribe-está situado en el tiempo de una lectura que se hace escritura. Al inicio esta lectura tiene la forma del desciframiento: "el manuscrito se hallaba en un estado lamentable, lleno de quemaduras de cigarrillo y manchas de café. Con una paciencia de paleógrafo logré poco a poco ir descifrando sus páginas” (481). Al final, cuando espera la llegada de Demetrio y escribe la narración, teme que algún dato no haya sido consignado en el diario: "Puede, por otra parte, haber aplazado esta visita, sin haberlo anotado en su diario” (483).

Finalmente, podemos decir siguiendo el trabajo de Bessière que "Demetrio" es la expresión de un caso, donde se pone a prueba la validez de las leyes temporales. La temporalidad, como sabemos, es el tópico por excelencia de la filosofía moderna, pues sólo adquiere su potencial de problematización en un universo secular. El hombre arrojado al mundo, del cual hablaron los existencialistas, es un sujeto ubicado en la problemática de la temporalidad que surge de la conciencia de una muerte que aparece como un espacio vacío, es decir, sin tiempo y menos sentido. Un lugar al que “Demetrio” nos conduce, dentro de las seguridades que permite el género fantástico (como todo género), haciéndonos tomar, como dice Bellemin-Noël, "por imaginario lo que, en última instancia, es lo real que rechazamos admitir” (139). Para Marius Carlen lo real, a donde le dirige la escritura, es Demetrio. Su existencia, que toma para el narrador la forma de una aporía temporal, representa la muerte, lo sin sentido. En términos literarios hablamos del fin de la escritura: los puntos suspensivos con que la narración finaliza (“Demetrio ya está aquí...”), metaforiza el encuentro con lo real. Un encuentro que tiene la forma del fantasma en la escritura porque se hace con figuras: una metáfora que también podría ser una prosopopeya. La metáfora nos sugiere un más allá, el lugar de existencia de Demetrio; la prosopopeya nos revela a Demetrio como la muerte, es decir, como un vacío. Una muerte que ante todo es una expresión de ignorancia, pues como nos recuerda Paul De Man, "La muerte es un nombre que damos a un apuro lingüístico” (118).

CODA

¿Qué función cumple lo fantástico en la narrativa de Ribeyro? Lejos de ofrecer una solución completa a esta pregunta, el presente artículo intenta llamar la atención sobre algunos puntos. En primer lugar, es importante liberar al trabajo narrativo de Ribeyro de los rótulos que, salvo algunas excepciones, le ha impuesto el discurso crítico. Como se ha señalado, la crítica, más que describir o explicar el funcionamiento de los textos ribeyranos ha insistido de manera categórica en algunos temas por los que transita la obra del peruano, forzando la interpretación dentro de coordenadas ideológicas afines con el realismo sociológico. En este intento, que se explica en la tarea que la historia literaria ha dado a la literatura en el Perú, a saber, la formación de una identidad nacional, la crítica parece más un trabajo preceptivo que un ejercicio que explique las condiciones en que determinada ficción surge.

En segundo lugar -y frente a esta tendencia-, nuestra atención a lo fantástico intenta explicar su relación con toda la obra de Ribeyro, por lo demás prolífica, si consideramos los diferentes senderos que su escritura ha transitado. Así, estudiando no sólo el trabajo literario, 
sino también el denominado metaliterario (opiniones literarias en su diario, cartas y entrevistas), podemos observar un debate acerca de cuál era la representación más adecuada para su ficción. De hecho, la elección de Ribeyro se declara realista, pero su producción lo muestra oscilante entre lo propiamente fantástico y sus logros dentro de la poética realista. En consecuencia, no está demás constatar que lo fantástico es un elemento de tensión que permite especificar su narrativa, pues, en cierta medida, la presencia de lo fantástico es un espacio de fuga que diferencia su escritura, como también lo es la presencia de lo autobiográfico.

En este rescate de la presencia de lo fantástico -y este es mi tercer punto-, no debe dejarse de estudiar a “Demetrio”, el cuento fantástico de Ribeyro de más acabada factura. De la mano de la retórica del diario íntimo, que genera una tensión especial a lo largo del texto, esta narración muestra claramente cómo el acontecimiento fantástico genera una transgresión en el universo ideológico de los personajes. Se trata de un lugar de conflicto que especifica a los personajes de Ribeyro y se expresa como un choque y/o un desfase entre un mundo cambiante e inestable que no se deja atrapar por valores y sistemas ideológicos de otras épocas.

BiBLIOGRAFÍA

Alazraki, Jaime. “¿Qué es lo neofantástico?”. Teorías de lo fantástico. David Roas, ed. y trad. Madrid: ARCO/LIBROS, 2001. 265-82.

Angvik, Birger. La narración como exorcismo: Mario Vargas Llosa, obras (1963-2003). Lima: FCE, 2004.

Barthes, Roland. S/Z. Madrid: Siglo XXI, 1980.

Bellemin-Noël, Jean. “Notas sobre lo fantástico (textos de Théophile Gautier)”. Teorías de lo fantástico. David Roas, ed. y trad. Madrid: ARCO/LIBROS, 2001. 107-40.

Belevan, Harry. “Breves palabras para convencer a los convencidos”. Antología del cuento fantástico peruano. Harry Belevan, ed. Lima: U Nacional Mayor de San Marcos, 1977. XI-LVII.

Bessière, Irene. "El relato fantástico: forma mixta de caso y adivinanza”. Teorías de lo fantástico. David Roas, ed. y trad. Madrid: ARCO/LIBROS, 2001. 83-04.

Bryce Echenique, Alfredo. “El arte genuino de Ribeyro”. Cuentos Completos. Julio Ramón Ribeyro. Madrid: Alfaguara, 1994. 11-15.

Coaguila, Jorge. Julio Ramón Ribeyro. Las respuestas del mudo (entrevistas). Lima: Campodónico, 1998.

Ribeyro: La palabra inmortal. Lima: Campodónico, 1996.

Delgado, Washington. “Fantasía y realidad en la obra de Ribeyro”. Julio Ramón Ribeyro. La palabra del mudo. Cuentos 52/72. Lima: Milla Batres, 1973. XI-VI.

García Muñoz, Gerardo. Julio Ramón Ribeyro: Cinco claves de su cuentística. Torreón, México: U Iberoamericana Torreón, 2003.

Genette, Gérard. Figuras III. Carlos Manzano. Barcelona: Lumen, 1989.

Higgins, James. Cambio social y constantes humanas. Lima: PUCP, 1991.

Jackson, Rosie. “Lo ‘oculto’ de la cultura”. Teorías de lo fantástico. David Roas, ed. y trad. Madrid: ARCO/LIBROS, 2001. 141-52. 
Kristal, Efraín. “El narrador en la obra de Julio Ramón Ribeyro”. Revista de Crítica Literaria Latinoamericana 10/20 (1984): 155-69.

Leujene, Philippe. “El pacto autobiográfico”. La autobiografía y sus problemas teóricos. Suplementos Anthropos 29. Ángel Loureiro. Barcelona: Anthropos, 1991. 47-61.

Loureiro, Ángel. La autobiografía y sus problemas teóricos. Suplementos Anthropos 29. Barcelona: Anthropos, 1991.

Luchting, Wolfgang. “Lo que dijo Ribeyro”. Julio Ramón Ribeyro. Las respuestas del mudo (entrevistas). Lima: Campodónico, 1998. 37-42.

Man, Paul de. “La autobiografía como desfiguración”. La autobiografía y sus problemas teóricos. Suplementos Anthropos 29. Ángel Loureiro. Barcelona: Anthropos, 1991. 113-17.

Márquez, Ismael P. y César Ferreira, eds. Asedios a Julio Ramón Ribeyro. Lima: Fondo Editorial de la Pontificia Universidad Catolica del Peru, 1996.

Minardi, Giovanna. La cuentística de Julio Ramón Ribeyro. Lima: BCR/La casa de cartón, 2002.

Ortega, Julio. Correo electrónico personal. 31 de Octubre de 2005. “Los cuentos de Julio Ramón Ribeyro”. Cuadernos Hispanoamericanos 417 (marzo 1985): 128-45.

Oviedo, José Miguel. “La lección de Ribeyro”. Quimera 37 (abril 1984): 58-9.

Ribeyro, Julio Ramón. Antología personal. Lima: Fondo, 1994. Cartas a Juan Antonio. Tomo I. 1953-1958. Lima: Campodónico, 1996. Cartas a Juan Antonio. Tomo I. 1958-1970. Lima: Campodónico, 1998. Cuentos Completos. Madrid: Alfaguara, 1994.

"Demetrio". Cuentos Completos. Madrid: Alfaguara, 1994. 481-83. Dichos de Luder. Presentados por Julio Ramón Ribeyro. Lima: Campodónico, 1989. “En torno a los diarios íntimos”. La caza sutil. Lima: Milla Batres, 1975. 9-13. La palabra del mudo. Cuentos 52/72. 2 vols. Lima: Milla Batres, 1973. La tentación del fracaso. Barcelona: Seix Barral, 2003. Prosas apátridas aumentadas. Lima: Milla Batres,1978.

Roas, David. “La amenaza de lo fantástico”. Teorías de lo fantástico. David Roas, ed. y trad. Madrid: ARCO/LIBROS, 2001. 7-44.

Teorías de lo fantástico. David Roas, ed. y trad. Madrid: ARCO/LIBROS, 2001.

Rodero, Jesús. "Del juego y lo fantástico en algunos relatos de Julio Ramón Ribeyro”. Revista Iberoamericana LXVI/190 (enero-marzo 2000): 73-91.

Los márgenes de la realidad en los cuentos de Julio Ramón Ribeyro. New Orleans: U of the South, 1999.

Rosario Alfani, María. “Escritura en contumacia: La escritura horizontal de Julio Ramón Ribeyro”. Revista de Crítica Literaria Latinoamericana 5/10 (1979): 137-42.

Vidal, Luis Fernando. "Ribeyro y los espejos repetidos”. Revista de Crítica Literaria Latinoamericana 1/1 (1975): 73-87.

Todorov, Tzvetan. “Definición de lo fantástico”. Teorías de lo fantástico. David Roas, ed. y trad. Madrid: ARCO/LIBROS, 2001. 47-64. 
“Lo extraño y lo maravilloso”. Teorías de lo fantástico. David Roas, ed. y trad. Madrid: ARCO/LIBROS, 2001. 65-81.

Los géneros del discurso. Jorge Romero León, trad. Caracas: Monte Avila, 1991. Tumi, Mito. “El asedio a la fama”. Julio Ramón Ribeyro. Las respuestas del mudo (entrevistas). Lima: Campodónico, 1998. 289-94.

Zavaleta, Carlos Eduardo. "Las fantasías de Hawthorne. Prólogo y traducción de los Cuardernos américanos”. Letras 65 (1965): 63-95. 